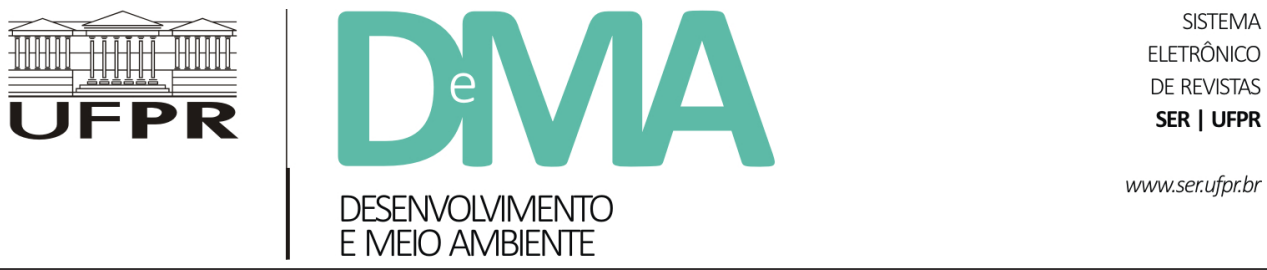

\title{
Novo desenvolvimentismo e conflitos ambientais na Baía de Guanabara: o Complexo Petroquímico do estado do Rio de Janeiro (COMPERJ) e os pescadores artesanais
}

\section{New Developmentalism and Environmental Conflicts in Guanabara Bay: The Petrochemical Complex of the State of Rio de Janeiro (COMPERJ) and the Artisanal Fishermen}

\author{
Thiago Wentzel de Melo VIEIRA ${ }^{1 *}$, Giuliana Franco LEAL ${ }^{2}$, Rodrigo Lemes MARTINS² \\ ${ }^{1}$ Universidade Estadual do Rio de Janeiro (UERJ), Rio de Janeiro, RJ, Brasil. \\ ${ }^{2}$ Universidade Federal do Rio de Janeiro (UFRJ), Macaé, RJ, Brasil. \\ *E-mail de contato: wentzel_bio@hotmail.com
}

Artigo recebido em 2 de junho de 2016, versão final aceita em 6 de setembro de 2017.

\begin{abstract}
RESUMO: $\quad$ Na última década ocorreram mudanças na estratégia de desenvolvimento econômico brasileiro ocorreram na última década, através da criação de grandes projetos de infra-estrutura. O governo federal brasileiro lançou todos esses projetos em um Programa denominado "Programa de Aceleração do Crescimento" (PAC), esta estratégia teve como objetivo aumentar a produção, bem como o seu escoamento. A nova reestruturação territorial, realizada pelas políticas federais, marca um novo contexto de desenvolvimento - denominado "novo desenvolvimentismo" - baseado, principalmente, pela construção de grandes empreendimentos petroquímicos, usinas elétricas, rodovias, entre outros. No presente estudo, questionamos o Complexo Petroquímico do Estado do Rio de Janeiro (COMPERJ). O COMPERJ ilustra um caso típico de conflitos ambientais comuns no conjunto de transformações definidas pelo PAC, principalmente devido a instituição de áreas de exclusão de pesca na Baía de Guanabara. Este empreendimento produziu um conflito ambiental com os grupos de pesca, suas diferentes formas de apropriação e uso do espaço, que é uma condição de existência de seus meios de subsistência.
\end{abstract}

Palavras-chave: PAC; COMPERJ; novo desenvolvimentismo; pescadores artesanais; conflitos ambientais.

ABSTRACT: Changes in the Brazilian economic development strategy occurred in the last decade through the creation of large infrastructure projects. The Brazilian federal government launched all these projects in a Program called "Programa de Aceleração do Crescimento - PAC" (Growth Acceleration Program). This strategy aimed to 
increase production, as well as its distribution. This new territorial restructuring carried out by federal policies marks a new development context called "new developmentalism", based mainly on the construction of large petrochemical ventures, power plants and highways, among others. In the present study, the construction of the Complexo Petroquímico do Estado do Rio de Janeiro - COMPERJ (Petrochemical Complex of the State of Rio de Janeiro) is discussed. The COMPERJ illustrates a typical case of environmental conflict associated to the array of transformations determined by the PAC, in this case, due mainly to the institution of fishing exclusion zones in the Guanabara Bay. This project has produced an environmental conflict with the fishing groups and their various forms of appropriation and use of space, which is a condition of existence of their means of subsistence.

Keywords: PAC; COMPERJ; new developmentalism; artisanal fishermen; environmental conflicts

\section{Introdução}

Os países da América latina têm buscado estratégias, sobretudo de caráter macroeconômico, a fim de promover um desenvolvimento que os eleve a condição de países desenvolvidos. Essa busca configura um novo ciclo da acumulação capitalista na América Latina, alicerçado, novamente, na retórica desenvolvimentista. Esse ciclo, de certa forma, "pega carona" na alta dos preços de matéria prima e a crescente demanda de mercados consumidores, principalmente da China.

No caso brasileiro, a intensificação da pauta desenvolvimentista se consolida, principalmente, após o ano de 2007 - com o lançamento do Programa de Aceleração do Crescimento $\left(\mathrm{PAC}^{1}\right)$. $\mathrm{O}$ PAC compreende um conjunto de empreendimentos de cunho estratégicos para o desenvolvimento, e que se ancoram diretamente nas perspectivas geradas pela recente descoberta de volumosas reservas de petróleo, na chamada camada do Pré-Sal - que elevou o Brasil a uma posição de destaque no mercado energético global.

A fim de buscar compreender esse momento de desenvolvimento do Brasil, nos apropriamos do que vem sendo chamado de "novo-desenvolvimentismo" e que vem se configurando desde a última década como um novo projeto político e ideológico, no qual o Estado desempenha um papel mais forte e ativo na economia. Deste modo, garantindo um mercado forte e o financiamento de atividades produtivas (Siscú et al., 2007), assim como uma política industrial, com aumento da infraestrutura física e das matrizes energéticas, aliado a políticas de combate à fome e a desigualdade social.

Este trabalho corrobora a ideia de que esse novo projeto desenvolvimentista tem tido como consequência a intensificação de conflitos ambientais, aqui entendidos como a "inserção da natureza no interior do campo dos conflitos sociais" (Acselrad, 2004, p. 9), e que ameaça os modos de vida de grupos sociais tradicionais causadas por grandes projetos de desenvolvimento. Tais conflitos são deflagrados, principalmente, por questões relativas ao acesso e controle dos bens, dos espaços naturais e dos de uso comum (que têm se tornado privados), no bojo de processos expropriatórios. Estes conflitos emergem em razão da intensificação da exploração da natureza, assumida por governos progressistas que chegaram ao poder dos países la-

${ }^{1}$ Os empreendimentos do Programa de Aceleração do Crescimento podem ser consultados na íntegra em http://www.pac.gov.br/i/b8. 
tinos pós anos 2000 (Algranati \& Seoane, 2013).

Partindo de um trabalho investigativo, propõese aqui analisar um caso específico, em que as políticas desenvolvimentistas do PAC entram em choque com um grupo social. O objetivo deste trabalho é, portanto, compreender como se desenvolvem os conflitos ambientais envolvendo os pescadores artesanais da Baía de Guanabara e o Complexo Petroquímico do Estado do Rio de Janeiro (COMPERJ), sob os auspícios da Petrobrás.

Como metodologia, foram utilizadas entrevistas semiestruturadas junto as lideranças das entidades pesqueiras da Baía de Guanabara - no caso, foram entrevistadas cinco lideranças pesqueiras, sendo quatro colônias e uma associação de pesca - entre os anos de 2013-2015. Essas, tem suas áreas de pesca confrontadas pelos atuais empreendimentos e enriquecidas pela observação participante e pesquisa exploratória documental, isto é, análise de documentos oficiais e técnicos, tanto do COMPERJ quanto dos empreendimentos que constituem a chamada infraestrutura auxiliar.

Neste artigo, será apresentado um breve histórico e as principais características do novo desenvolvimentismo no Brasil, com especial ênfase ao Programa de Aceleração do Crescimento. O Comperj será, então, apresentado e compreendido nesse contexto. Em seguida, serão discutidas as consequências de sua inserção na Baía de Guanabara, com especial enfoque às atividades e modos de vida dos pescadores artesanais. Por fim, os conflitos entre estes e o Comperj serão aprofundados.

\section{O Programa de Aceleração do Crescimento no contexto do novo desenvolvimentismo}

Para Harvey (2005), o problema recorrente do capitalismo é a ausência de oportunidades lucrativas que deem vazão ao processo de acumulação de capital. Diante disso, a expansão geográfica e a reorganização espacial criam tal oportunidade, muitas vezes garantindo e ampliando o próprio processo de acumulação, ao garantir sua expansão geográfica por meio de investimentos em infraestruturas físicas e sociais - que poderiam ser realizados pelo capital, mas que se consolidam com o financiamento e atuação do Estado, desonerando o capital privado.

Nessa perspectiva, o Estado é visto como arcabouço territorializado, no interior do qual agem os processos moleculares de acumulação do capital (Harvey, 2013). O Estado deve então ser "definido" como entidade política, o corpo político mais capaz de orquestrar arranjos institucionais e manipular as forças moleculares de acumulação de capital (Harvey, 2013). Para Sicsú et al. (2007), o papel ativo do Estado é fundamental na promoção do novo desenvolvimentismo.

Para Bresser-Pereira (2012), o novo desenvolvimentismo no Brasil inicia-se após os anos 2000, mais especificamente, conforme Pinho (2012), no primeiro governo Lula. Para Mercadante (2010), no primeiro governo Lula houve: a retomada dos investimentos públicos, a reconstrução do sistema de crédito interno, novas políticas de desenvolvimento industrial e tecnológico, estímulos ao setor privado à expansão dos investimentos, as políticas de renda e as de 
inclusão social. Além de haver o fortalecimento dos bancos públicos, como o Banco Nacional do Desenvolvimento Social (BNDES) - focado na indução e expansão dos investimentos -, o Banco do Brasil (visando a democratização do crédito) e a Caixa Econômica (atuando na implantação dos programas habitacionais).

Na concepção do novo desenvolvimentismo, fica evidente a atuação do Estado na implementação de políticas macroeconômicas defensivas que possam reduzir a sensibilidade do país à crises cambiais e políticas expansionistas, para assegurar o pleno emprego - como as políticas industriais. $\mathrm{O}$ novo desenvolvimentismo "não propõe a redução do Estado, mas a sua reconstrução, tornando-o mais forte, e mais capaz no plano político, regulatório e administrativo, além de financeiramente sólido." (Sicsú et al., 2007, p. 515). Propõe uma estratégia nacional que viabilize progresso técnico e novas técnicas de produção, sobretudo, com linhas de financiamento do Estado, aliados ao controle do câmbio a nível competitivo e um mercado forte (Sicsú et al., 2007).

De acordo com Bresser-pereira (2012), o Estado ganha protagonismo na condução dos investimentos, mas não descarta o setor privado. Neste contexto, o Estado:

Rejeita o laissez-faire liberal em relação à regulação dos mercados e aos investimentos na infraestrutura e nas indústrias de base, e defende o planejamento nessas áreas; um Estado que é inicialmente responsável por uma parte considerável dos investimentos, ficando o restante para o setor privado (Bresser-Pereira, 2012, p. 11).

Em princípio, pode-se dizer que o novo desenvolvimentismo pretende ser a construção de um "terceiro discurso", que destaca as falhas do nacional desenvolvimentismo e se posiciona com críticas ao Consenso de Washington ${ }^{2}$. Assim, o novo desenvolvimentismo pretende implementar um conjunto de reformas das políticas macroeconômicas e, também, das instituições.Visando, assim, fortalecer tanto o Estado como o mercado e, com isso, tornar o país mais competitivo no cenário internacional. (Mattei, 2011; Gonçalves, 2012).

Entretanto, é importante reconhecer que, embora de acordo com Bresser-Pereira (2006), o novo desenvolvimentismo não quer basear seu crescimento na exportação de produtos primários de baixo valor agregado; em vez disso, define como estratégia central a exportação de manufaturados ou produtos primários de alto valor agregado. Porém, o que verificamos na prática é o inverso, ou seja, a economia nacional insulada nos setores econômicos dos segmentos de commodities como petróleo, grãos, e minerais, intensivos na exploração dos recursos naturais.

De acordo com Mercadante (2010), em 2002 os produtos primários exportados representavam $19,40 \%$ do total exportado, enquanto em 2008 representava $28,3 \%$ das exportações. Veríssimo \& Xavier (2014), em análise dos dados de exportação brasileira, concluem que há uma crescente participação das commodities em detrimento de perda quase contínua nas exportações

\footnotetext{
${ }^{2}$ No ano de 2003, Bresser-Pereira estruturou o conceito de novo desenvolvimentismo, contrapondo-o tanto ao consenso de Washington quanto ao antigo desenvolvimentismo. O consenso de Washington é um conjunto de diretrizes repassadas por instituições financeiras de países do Norte para a América Latina, a partir do final da década de 1980, com a finalidade de rearranjar os Estados com o fim manifesto de sair da crise econômica.
} 
dos bens manufaturados. De acordo com os autores, em 1999, os commodities representavam 53,7\% das vendas externas do país e, em 2011, representavam $70,9 \%$. Cenário que sugere uma especialização da economia em bens intensivos de recursos naturais.

Houve, portanto, um aumento das exportações de produtos primários em detrimento de produtos processados, sobretudo, pela demanda norte americana e em função da inserção da China no comércio internacional, visto que ambos constituem os maiores demandantes de commodities brasileiros (Verissimo \& Xavier, 2014). Segundo Oreiro \& Feijo (2010), há uma perda da importância da indústria de transformação brasileira nos últimos 15 anos, devido a alta do preço dos commodities e dos recursos naturais no mercado internacional. Como consequência, a relação de troca entre os países que exportam produtos primários e os que exportam manufaturas tende a ser, em geral, adversa para os primeiros e tem tendência a piorar.

Cabe, aqui, situar o PAC como plano de metas propostas para o desenvolvimento do país, expressando o compromisso do Estado com as questões inerentes a recuperação do planejamento estratégico como instrumento de desenvolvimento, ou seja, o PAC recupera o papel indutor do investimento público para a alavancagem do investimento privado (Mercadante, 2010). Conforme Leher (2007). Além disso, o PAC obviamente - atua confirmando e consolidando o padrão de acumulação capitalista ao colocar o território nacional em liquidação para o capital e, também, ao atender seu interesse na exportação de commodities.

Na primeira década dos anos 2000, o Brasil assegurou o desenvolvimento com especialização na exportação de recursos naturais através de mecanismos de transferência da alta produtividade dos setores especializados em recursos naturais, para uma parte da economia em detrimento da geração de externalidades para o restante da economia (Acselrad, 2014).

Conforme Acselrad (2014), sob o discurso do novo desenvolvimentismo, encontram-se em expansão as fronteiras da exploração mineral, dos recursos energéticos e da água, além dos conflitos ambientais que têm se manifestado nos territórios em questão; são a expressão da emergência de críticas aos projetos de desenvolvimento que são enunciadas por sujeitos coletivos que se veem ameaçados ou em vias de expropriação. Intensificase, portanto, o uso capitalista das condições naturais como condições do processo de acumulação de riqueza abstrata e choca-se com outras formas de uso.

\section{A retomada do desenvolvimento e o Complexo Petroquímico do Estado do Rio de Janeiro}

A descoberta de novas jazidas de petróleo em camadas mais profundas que as atualmente exploradas - conhecidas como camadas do pré-sal -, em 2003, alterou significativamente o cenário de médio e longo prazo da cadeia produtiva petrolífera. O Brasil, que detinha, naquele momento, modestas reservas - em torno de 13 bilhões de barris -, rapidamente passou a estimar a existência de 30 bilhões de barris, e logo depois, 100 bilhões de barris nas porções do território definidos como águas ultraprofundas (Binzstok, 2012).

O Estado do Rio de Janeiro, por sua posição privilegiada em relação as principais bacias de 
produção de petróleo em água profundas e pela relativa alta quantidade de empresas, formando uma rede de suporte às atividades de extração e exploração de petróleo, tem atuado com vários arranjos - no sentido de manter o seu projeto de desenvolvimento territorial-, agregando os grandes projetos industriais e de infraestrutura. Para isso, planejou, em vários municípios limítrofes à Baia de Guanabara e ao município de Itaboraí, uma estrutura de múltiplas gerações articuladas em cadeia, o Complexo Petroquímico do Estado do Rio de Janeiro COMPERJ (Binzstok \& Wasserman, 2012).

O empreendimento, conduzido pela Petrobrás, é constituído por duas plantas de refino e uma petroquímica, que produzirão petroquímicos de primeira geração como, por exemplo: eteno, benzeno, propeno, butadieno e outros) e de segunda geração (polietilenos, polipropileno, estireno, etilenoglicol e outros (Domingues, 2012), a partir do petróleo de baixa qualidade (petróleo pesado) oriundo de poços da Bacia de Campos (Binzstok \& Wasserman 2012).

Esse projeto tornou-se um dos maiores projetos da história da Petrobrás e a quarta maior obra do PAC, ocupando uma área de $45 \mathrm{~km}^{2}$. Com base nas expectativas da Petrobrás, o conjunto de empreendimentos irá modificar a estrutura petroquímica brasileira e reduzirá a dependência do setor externo por insumos básicos, constituindose em um dos empreendimentos mais importantes do PAC. É importante salientar que, a realização do COMPERJ se dá por uma parceria entre a Petrobrás, o Grupo Ultra e o Banco Nacional do Desenvolvimento Econômico e Social (BNDES) (Dias et al., 2013).

Além da planta industrial localizada no município de Itaboraí, o COMPERJ conta com uma extensa infraestrutura-auxiliar composta por vários empreendimentos que funcionarão em conjunto com a planta principal em Itaboraí, e que estão sendo construídos de forma descentralizada, ou seja, espacializados por toda a região, inclusive no interior da Baía de Guanabara (Dias et al., 2013).

A chegada do COMPERJ e dos empreendimentos que constituem a infraestruturaauxiliar, vem submetendo a Baía de Guanabara a novas formas de impactos que, por sua vez, atingem diretamente os pescadores artesanais, que se veem em vias de expropriação de extensas faixas de uso para a navegação e pesca, culminando na exclusão do território pesqueiro.

Contudo, cabe destacar que, devido a crise das commodities, isto é, produtos primários e com baixo valor agregado, que atingiu a América Latina e, sobretudo, o Brasil nos últimos anos, seguido pela diminuição significativa da demanda chinesa desses commodities, agregado as subsequentes denúncias de corrupção realizadas pela operação lava-jato no país, inviabilizou ou atrasou grande parte das obras projetadas no PAC, como o COMPERJ. Assim, embora o empreendimento já tenha $80 \%$ de sua planta concretizada, não irá mais operar na capacidade prevista inicialmente.

\section{A infraestrutura-auxiliar do COMPERJ: novos recortes e restrições de uso da Baía de Guanabara}

Até o momento, o maior impacto acarretado pela construção do COMPERJ, do ponto de vista dos pescadores, tem sido a configuração de novas áreas de exclusão de pesca, principalmente, em função da infraestrutura-auxiliar, distribuída em 
pontos diferentes da Baía de Guanabara. Dentre as obras que reduzem a área de pesca, destacamse as que preveem a criação de extensas faixas de exclusão durante sua fase de implantação e/ou

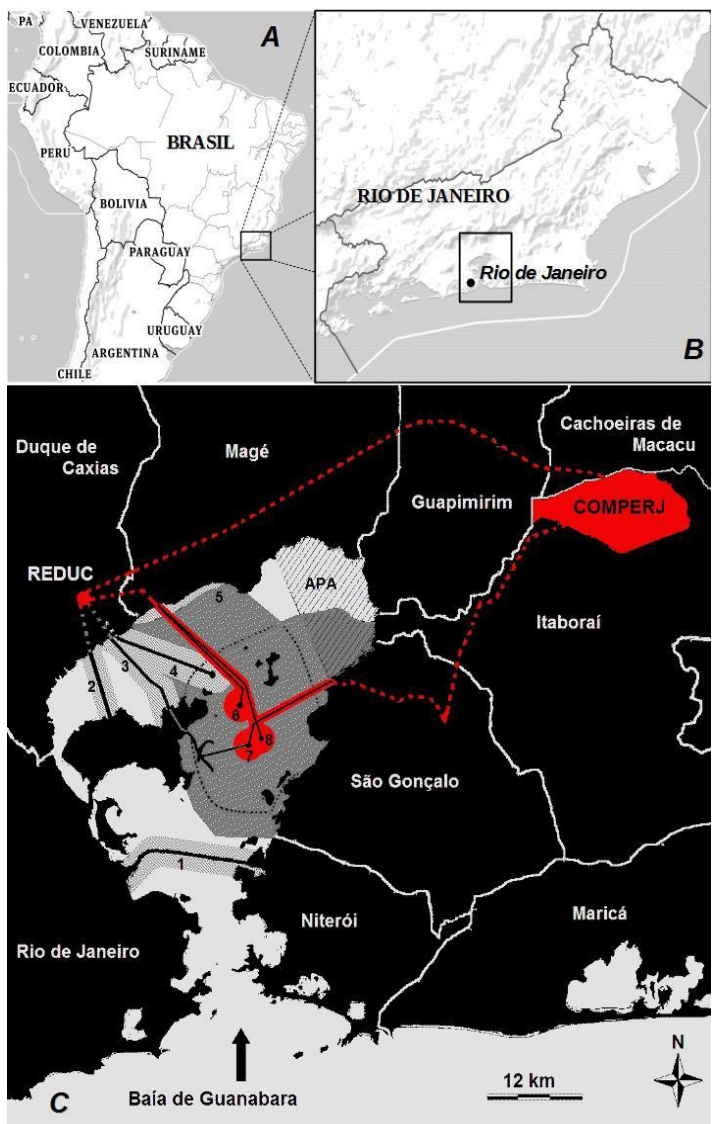

FIGURA 1 - Brasil (A), Estado do Rio de Janeiro (B) destacando a Baía de Guanabara (C), com as novas instalações do Complexo Petroquímico do Rio de Janeiro (COMPERJ), em vermelho: no espelho d'água, também em vermelho, as novas áreas de exclusão dos dutos e Terminal de Gás Natural Liquefeito (6), do Terminal Aquaviário da Ilha Comprida (7) e do Terminal Aquaviário da Ilha Redonda (8); em cinza escuro as Áreas de Influência Direta e Indireta do COMPERJ; em cinza claro a Área de Influência Direta de outros empreendimentos já estabelecidos: (1) ponte Rio Niteroi, (2 e 3) dutos da Refinaria de Duque de Caxias (REDUC), (4) Pier da Polibrasil e (5) REDUC. $\mathrm{Na}$ área hachurada a do espelho d'agua Área de Proteção Ambiental (APA) de Guapimirim. operação, como o Terminal Aquaviário da Ilha Comprida (TAIC), o Terminal Aquaviário da Ilha Redonda (TAIR), o Terminal de Gás Liquefeito Natural (GLN), o sistema de dutos, que corta o espelho d'água da Baía de Guanabara e o Projeto de Gás Liquefeito de Petróleo (GLP). Destaca-se que, estes empreendimentos estão sendo implementados de maneira simultânea na região, o que têm causado impactos sinergéticos sobre a atividade pesqueira na região.

Quanto as delimitações, elas funcionam de forma diferente para tipos díspares de empreendimento (conforme Tabela 1) e são tidos como necessárias para a diminuição do risco de acidentes que vão, desde colisões de embarcações até perda de apetrechos de pesca (Mineral, 2007; Bourscheid, 2009). O Estudo de Impacto Ambiental do empreendimento (Mineral, 2007) também ressalta que, durante toda a vida útil do empreendimento, será necessário estabelecer uma "zona de segurança" em torno das ilhas. Nessa zona de segurança, não será permitida a permanência de embarcações dentro do seu limite, salvo com autorização expressa da administração dos Terminais.Ademais, o Estudo de Impacto Ambiental não nega que por conta da criação de ambientes de exclusão permanente, o empreendimento irá afetar o meio socioeconômico, especialmente os pescadores da região (Tabela 2).

Entretanto, mesmo os impactos na atividade petroleira sendo amplamente reconhecidos nos documentos técnicos dos empreendimentos, nenhuma medida eficaz para compensá-los foi tomada pela Petrobrás no decorrer da construção dos empreendimentos. Tal afirmação pode ser confirmada no Inquérito Civil Público $\mathrm{n}^{\circ}$ 1.30.020.000044/2009-53 aberto pelo Ministério 
coloca em evidência a tomada de bens comuns e expropriação de grupos sociais. De acordo com Harvey, são características da acumulação por espoliação, a escalada da destruição dos recursos ambientais globais (terra, ar, água) e a mercadificação da natureza que tem sido empregada em diversas regiões do mundo, em uma nova onda de expropriação das terras comuns (Harvey, 2013).

Para Harvey, a acumulação por espoliação é um processo de apropriação e privatização dos ambientes comuns, que resulta na desvalorização e destruição dos meios de vida anteriormente viáveis. Assim, transformando em ativos os bens coletivos e direcionados ao desenvolvimento capitalista, contando com o forte apoio dos poderes do Estado em função de um modelo de desenvolvimento alheio a reprodução da vida nos territórios anteriormente públicos, comunais. O processo exemplar é conhecido como privatização, que promove a venda dos, outrora, denominados bens comuns e coletivos (Almeida-Filho \& Paulani, 2011).

Este processo permite dar conta do renovado e ampliado processo de mercantilização (privatização), que caracteriza a atual fase do capitalismo no continente Sul Americano. Ainda neste sentido, existem as formas de acumulação por espoliação, que caracteriza-se pela lógica de despojo e saqueio dos bens comuns naturais. Por consequência, esse processo tem imposto mudanças territoriais e culturais, eclodindo em conflitos sociais em torno dos bens comuns naturais. Nas imediações de grandes empreendimentos, têm se configurado diversas ações coletivas ${ }^{3}$, empreendidas na defesa dos bens comuns (Seoane, 2013).

Neste sentido, faz-se necessário observar a Baía de Guanabara como um bem comum, mas que vem passando nos últimos anos por um notório aumento das concessões de caráter privatista do uso deste espaço coletivo, em função dos novos usos exigidos pelos empreendimentos petroquímicos que aportam na região, e que resultam na diminuição das áreas de pesca. Chaves (2011), utilizando uma metodologia de "mapeamentos participativos", chega a seguinte conclusão, no que tange as novas áreas exclusão da pesca impostas pelos empreendimentos que constituem a infraestruturaauxiliar:

Os mapas mostram que, apenas $25 \%$ (vinte e cinco por cento), aproximadamente, da Baía de Guanabara, está livre de qualquer restrição. Logo, estas áreas são livres para a pesca. Incluindo a Área de Influência Indireta (AII) dos dutos e terminais, esta área reduz para 12\% (Doze por cento). (Chaves, 2011, p. 154).

Além das novas áreas de exclusão, propostas pelos novos empreendimentos petroquímicos que aportam agora na Baía de Guanabara, é importante reconhecer que a Baía de Guanabara é uma região onde, historicamente, desembocam múltiplos usos. E que, também, refletem na maximização do cerceamento e exclusão da atividade pesqueira, tais como, a Estação Ecológica da Guanabara (ESEC), os estaleiros, o aeroporto do Galeão, os terminais privados, o entorno da Refinaria Duque de Caxias (REDUC) e as bases militares.

De acordo com Chaves (2011), “a marinha po-

\footnotetext{
${ }^{3}$ Alonso \& Costa (2002) chamam de lógica da ação coletiva ao modo pelo qual o entrecruzamento não intencional de diversas linhas de ação configura padrões de organização e comportamento, fazendo com quem os agentes coletivos formem-se no decorrer do processo conflitivo e em oposição um aos outros. Compreende-se a ação coletiva enquanto um fenômeno capaz de trazer mudanças às estruturas sociais e que tem como pivô a assimetria de forças.
} 
sui regras de circulação no interior da Baía, as quais são materializadas através de bóias sinalizadoras e placas, restringindo a aproximação de qualquer embarcação nas áreas de seu domínio". As condições que a pesca está submetida na Baía de Guanabara são expressadas nas falas das próprias lideranças pesqueiras:

Nós hoje perdemos vários pontos de pesca. Tem a área do aeroporto, que não pode pescar na cabeceira do aeroporto, pois o peixe traz as aves que ficam ali sobrevoando e isso pode causar acidentes. Tem as várias plataformas. Temos o Boqueirão que não podemos pescar porque lá é uma área de segurança nacional, é área da marinha e se entrar eles atiram, prendem a embarcação. Tem uma área que é da união e é de proteção ambiental que é a APA Guapimirim. Aí acaba que gente fica sem área pra pescar. Eles nos impedem de pescar. Eles criam isso e nos tiram a área de pesca. Se você olhar na baía de Guanabara hoje, há milhares de navios, só que a gente não consegue pescar ali, por causa das correntes. Aí o que sobrou pra gente foi o fundo da baía de Guanabara e hoje começaram a construção de todos esses empreendimentos no fundo da baía (Liderança da colônia Z-9.).

Hoje só tem "sai daí," "chuta"; "sai fora”, "essa área é minha". A marinha mete bala de um lado, o INEA sai pra pegar pescador (Liderança da colônia Z8).

Desta forma, conclui-se que, a apropriação da Baía de Guanabara para fins específicos tem gerado a exclusão e expropriação dos pescadores da região há décadas, cerceando o acesso aos recursos e inviabilizando as formas de reprodução de seus modos de trabalho e de vida. A chegada do COMPERJ e as instalações dentro da Baía de Guanabara, intensificaram esse processo levando os pescadores a engajaram-se em ações que materializam o conflito ambiental na região.

\section{Da precarização da atividade pesqueira ao conflito ambiental: A Baía de Guanabara em disputa.}

Se a Baía de Guanabara é mundialmente famosa, como importante elemento da paisagem da cidade do Rio de Janeiro, o mesmo já não pode ser dito para aqueles que vivem das suas águas. Já faz décadas que aqueles que subsistem de seus recursos são confrontados com a precarização da atividade pesqueira, principalmente devido ao crescimento das atividades industriais do entorno, que hoje se constitui no segundo maior parque industrial do País, com cerca de 14000 indústrias e 7,8 milhões de habitantes. Além de duas refinarias (Refinaria de Duque de Caxias e a Refinaria de Manguinhos), diversos terminais marítimos de petróleo e gás e zonas portuárias (Barrocas \& Wassermam, 1995).

No que tange ao reconhecimento por parte das agências do Estado quanto a importância da atividade da pesca, destaca-se a falta de dados por parte dos órgãos governamentais sobre a quantidade de pescadores em atividade na região. Assim, o IBAMA cita cerca de 2.200 pescadores (IBAMA, 2002), enquanto o estudo da Petrobrás indica existirem 7.719 (PLANAVE, 2010). Tais dados demonstram-se ainda mais discrepantes quando considerados os dados sobre a quantidade de pescadores associados às colônias e associações de pesca (Tabela 3).

A estimativa de trabalhadores da pesca representam, muitas vezes, famílias cujos modos de vida são, agora, confrontados com o cerceamento desse espaço comum. Assim, impactando diretamente em sua renda e projetos, "formas preexistentes de apropriação do espaço e 
TABELA 3 - Entidades de pesca da Baia de Guanabara estudadas e a quantidade de pescadores associados.

\begin{tabular}{ccc}
\hline Instituição & Local & Quantidade de pescadores \\
\hline Colônia Z8 & Niterói e São Gonçalo & 13000 \\
Colônia Z9 & Magé (Mauá) & 1800 \\
Colônia Z11 & Rio de Janeiro (Penha) & 600 \\
Associação de Homens e Mulheres do Mar (AHOMAR) & Magé (Mauá) & 4200 \\
Total & & $\mathbf{1 9 6 0 0}$ \\
\hline
\end{tabular}

em particular, do uso do território" (Bartra, 2013, p. 713). Neste sentido, entender o conflito em questão é, sobretudo, entender como os pescadores da região começam a reivindicar a Baía de Guanabara como garantia da existência de seus modos de vida, considerando que o COMPERJ chega à região como um movimento de reestruturação territorial, mas que entra em choque com os pescadores que tiram dela seu sustento.

A Baía de Guanabara constitui-se, então, em um espaço no qual se constrói coletivamente uma nova organização social, onde os novos sujeitos se constroem, instituindo seu espaço e apropriando-se dele material e simbolicamente (Zibéchi, 2003). Trata-se de conflitos que surgem das distintas práticas de apropriação técnica, social e cultural do mundo material, e que a base cognitiva para os discursos e as ações dos sujeitos, neles envolvidos, configura-se de acordo com suas visões sobre a utilização do espaço (Zhouri et al., 2005), onde a categoria meio ambiente é atravessada por sentidos socioculturais e interesses diferenciados.

Portanto, trata-se de um espaço comum de recursos, só que exposto a formas de apropriação, uso material e simbólico que variam (Acselrad, 2014). Isto é, o ambiente é apropriado de distintas maneiras, segundo os modos de usos e significação apresentados pelos diferentes grupos sociais.
De acordo com Henri Acserald os conflitos ambientais são:

Aqueles envolvendo grupos sociais com modos diferenciados de apropriação, uso e significação do território, tendo origem quando pelo menos um dos grupos tem a continuidade das formas sociais de apropriação do meio que desenvolvem ameaçada por impactos indesejáveis - transmitidos pelo solo, água, ar ou sistemas vivos - decorrentes do exercício das práticas de outros grupos (Acserald, 2004, p. 26).

O conflito expressa um processo de construção permanente das práticas sociais, conforme Bourdieu: "o mundo social, com suas divisões, é algo que os agentes sociais têm a fazer, a construir, individual e, sobretudo coletivamente, na cooperação e no conflito" (Bourdieu, 2011, p. 24). Trata-se, assim, da imediata manifestação dos antagonismos presente nas classes, que se dá através de um processo político e de mobilização, resultando em uma "luta de classificações" (Bourdieu, 2011, p. 26), visando impor uma visão do mundo social.

Em contexto de conflitividade socioambiental, de acordo com Lopes (2006), são as populações mais vulneráveis aos riscos e impactos socioambientais que vão apresentar apropriações criativas e novas formas de associatividade em torno das questões socioambientais (Lopes, 2006). 
Ao verem a inviabilização dos seus modos de vida e da prática da pesca, pela consolidação de novos empreendimentos, os pescadores se engajaram na luta social. Dessa forma, dando visibilidade à realidade que a pesca não está submetida. Após testemunhar o acúmulo de violações ambientais, os pescadores da Baía de Guanabara começaram a se reconhecer como atores fundamentais de resistência local (Dias et al. 2013).

Diante da atual realidade, enfrentada pelos pescadores da Baía de Guanabara, estes vêm fazendo uso de diversas estratégias de luta, como barqueatas (manifestações realizadas no mar com pequenos barcos de pesca), manifestações em frente a prédios públicos do governo e da Petrobrás. Além de pedidos de instauração de inquéritos em órgão jurídicos, como o Ministério Público Federal, onde já tramita uma ação civil pública e um inquérito civil público.

As entidades de pesca da Baía de Guanabara começaram a se manifestar, de alguma maneira, contra as novas pressões que estão submetidas em função dos novos empreendimentos - conforme afirmado pelas lideranças das colônias Z9 e Z8. Até então, estas são as mais impactadas pelos empreendimentos, visto que a região que mais recebeu estruturas do Comperj compreende, justamente, a região do leste da Baía de Guanabara e exatamente nas áreas de pesca tanto da colônia Z9 quanto da Z8.

Nós fizemos várias manifestações na frente do prédio da Petrobrás e da justiça, no centro do Rio de Janeiro, pela demora da indenização judicial que diz respeito à pesca e o acidente de óleo de 2000. A gente faz essas manifestações pra que a Petrobrás lembre-se da gente, que existe pescador. A gente sabe que a baía não é nossa, ela é da união. Então, assim como a gente tem o direito de pescar o governo tem o direito de mandar fazer obra. Mas, tem que arrumar um meio de podermos conviver, o progresso que são esses empreendimentos e a pesca. Nós hoje perdemos vários pontos de pesca (Liderança da colônia Z9). Nós estamos se mobilizando sim. Já fizemos, inclusive, duas barqueatas na Baía da Guanabara. Nós estamos se mobilizando, mas o poder econômico dessa empresa é muito grande. Do jeito que esta é o extermínio de uma tradição dentro de uma baía tão rica que está nas mãos do petróleo, das empresas petrolíferas. (Liderança da colônia Z8).

Assim, os pescadores vêm se articulando em torno das suas unidades representativas, isto é, as colônias. Também, vêm ensejando novas associações de pesca, adotando estratégias de resistência que dão materialidade ao conflito ambiental, que se dá pela defesa de seus modos de vida - que também está diretamente condicionada à defesa da Baía de Guanabara, mas que não são reconhecidos pelos agentes modernizadores como legítimos, e que mereceriam supostamente ser sacrificados em nome do projeto desenvolvimentista representado no COMPERJ. A ação dos pescadores adquire, assim, feições políticas pela organização e produção de estruturas de grupo e redes de interdependência, ou estruturas de mobilização (Alonso \& Costa, 2002).

É importante mencionar também que, no bojo do processo conflitivo, constituem-se novas entidades de pesca, com destaque para a Associação Homens e Mulheres do Mar (AHOMAR), considerada como a mais combativa entidade pesqueira na Baía de Guanabara (Herculano, 2012). A associação surge no bojo do conflito, e sua criação ocorreu em razão do cenário de extrema degradação da Baía de Guanabara - e que conta com enorme participação da Petrobrás -, principalmente após 
o acidente de 2000, afetando diretamente a pesca na região. A entidade foi criada efetivamente no decorrer do conflito ambiental, conforme afirma a liderança da AHOMAR:

A associação veio pra poder fazer a diferença. Fazer a fala que as outras entidades por vários motivos desconhecem ou não querem fazer. Uma fala bem critica da questão. Porque o empreendimento está ali? Porque nós não somos compensados? Cadê as compensações que deveriam estar no processo de licenciamento ambiental? Porque o pescador tem que sair, não existe outra alternativa? AAHOMAR vem fazendo essa fala pelos pescadores da região, especificamente sobre a exclusão da pesca provocada por empreendimentos off shore (Liderança da AHOMAR,).

Destaca-se a importância da AHOMAR no episódio ocorrido em abril de 2009, quando cerca de quarenta pescadores da associação reuniram-se na praia de Mauá (município de Magé) com seus barcos de pesca, com o objetivo de paralisar as obras de construção do duto de gás GLP pela Petrobrás, que estavam sendo implementadas pelo Consórcio GLP - Submarino. A paralisação durou mais de 40 dias e a construção deste duto de GNL não chegou a ser efetivada - indo, a decisão, parar em âmbito judicial.

O caminho da representação judicial via Ministério Público Federal (MPF), também foi usado pela associação, onde os pescadores entraram com uma Ação Civil Pública contra a Petrobrás, questionando as licenças ambientais dos empreendimentos e solicitando a suspensão das obras de implantação dos dutos.

O inquérito civil público $\mathrm{N}^{\circ}$ 1.30.020.000044/2009-53, foi instaurado em 27 de abril de 2009 a partir de representação encaminhada pela AHOMAR ao Ministério Público Federal (MPF), por meio da qual são noticiados danos ambientais e socioeconômicos decorrentes de diversos empreendimentos realizados ao longo dos anos pela Petrobrás na Baía de Guanabara e em seu entorno - sem que os impactos socioambientais causados tenham sido, devidamente, avaliados e compensados.

A representação, no entanto, foca-se nos Projetos GNL e GLP, que atingem o mesmo ambiente ecológico. Esses, tendo como impacto ambiental previsto para a fase de implantação, a impossibilidade do exercício da atividade nas rotas pesqueiras atingidas pelos trabalhos de reboque e afundamento de trechos de dutos submarinos.

O MPF agendou uma reunião, no dia 23/09/2009, com os atores envolvidos, AHOMAR e a Petrobrás, mas a empresa se recusou a fazer o acordo. Diante disso, o MPF propôs a Ação Civil Pública n. ${ }^{\circ}$ 2009.51.14.000500-7, pleiteando indenização para 96 pescadores diretamente impactados pelo empreendimento por morarem na praia de Mauá e, além disso, que a Petrobrás refizesse os estudos constando todos os impactos dos seus empreendimentos sobre a pesca na baía de Guanabara, bem como as medidas mitigatórias e compensatórias que deverão ser adotadas.

\section{Considerações finais}

$\mathrm{O}$ atual modelo de desenvolvimento que se consolida com os grandes empreendimentos projetados no PAC, tem maximizado os conflitos ambientais no país. Conforme Zhouri et al. (2005), trata-se de um modelo de desenvolvimento que está assentado na produção e exportação de mercadorias 
(commodities) e que traz embutido as fragilidades deste modelo em dar conta dos "custos reais" do crescimento econômico projetado principalmente no PAC (Acselrad, 2014).

Constata-se a prevalência das ambiguidades do desenvolvimento, que agora se reinventa sob o conceito de novo desenvolvimentismo, mas que traz consigo velhas contradições - como os impactos socioambientais que acometem, amiúde, aqueles grupos mais frágeis socioeconomicamente. Tais grupos são, então, tratados como um entrave, seus modos de vida são tidos como impedimento para a geração de novos empregos e a melhoria da arrecadação das receitas, esperados a partir da implantação dos grandes projetos de desenvolvimento (Silva, 2012).

Assim, a exclusão do território pesqueiro (Dias et al., 2013) tem sido maximizada em função da magnitude espacial das novas plantas industriais, que impõem extensas faixas marinhas de restrição de uso da Baía de Guanabara. Afetam, também, pontos de captura do pescado, ficando a prática da pesca cada vez mais confinada a um pequeno espaço.

Ao situarmos a Baía de Guanabara enquanto um bem de uso comum e, portanto, coletivo, o conflito ambiental traz - no bojo - um processo que pretende dar um uso dominante a área e, automaticamente, exclui a presença de outros usos. No contexto da "acumulação por espoliação", observa-se a tomada dos espaços de uso comum e coletivos, isto é, a Baía de Guanabara, tornando-a num ativo para a acumulação capitalista, especialmente a indústria do petróleo e gás, resultando na espoliação dos pescadores artesanais que se deparam com ameaças, tanto de seus modos de trabalho quanto da própria existência da categoria profissional dos pescadores artesanais.

Diante da intensificação do processo de privatização da Baía de Guanabara, os pescadores emergem na esfera pública, contestando essa lógica de desenvolvimento, tal que sacrifica seus modos de vida. Em consequência, as lutas travadas contra a privação destes espaços dizem respeito aos direitos ambientais da população e a garantia do caráter coletivo do meio ambiente (Acselrad, 1993).

Em suma, verifica-se a inviabilização, sobretudo, de certas práticas espaciais (Acselrad, 2013), de forma que a transformação socioespacial da Baía de Guanabara para atender a cadeia produtiva de petróleo e gás, se choca com a prática pesqueira, resultando num conflito entre os diferentes projetos de uso e significação da baía apresentado pelos atores sociais envolvidos.

\section{Agradecimentos}

Agradecemos a leitura crítica e frutífera de Diôgo Lemes Martins e a Coordenação de Aperfeiçoamento de Pessoal de Nível Superior (Capes), que fomentou a pesquisa.

\section{Referências}

Acselrad, H. Ecologia direito do cidadão: coletânea de textos. Rio de Janeiro. 1993.

Acselrad, H. Conflitos ambientais no Brasil. Rio de Janeiro: Relume Dumará, 2004.

Acselrad, H. Prefácio. In: Malerba, J.; Raulino, S. (Orgs.). 50 anos da refinaria de Duque de Caxias e a expansão da indústria petrolifera no Brasil: conflitos socioambientais no Rio de Janeiro e desafios para o país na era do Pré-sal. 
FASE, Rio de Janeiro. 2013.

Acselrad, H. Disputas cognitivas e exercício da capacidade critica: o caso dos conflitos ambientais no Brasil. Sociologias, 16(35), 84-105, 2014.

Algranati, C.; Seoane, J. Disputas socioambientales: câmbios y continuidades em laconflitividad social em América Latina. In: Seoane, J.; Tardei, E.; Algranati, C. (Orgs.). Extractivismo, despojo y crisis climático: desafios para lós movimientossociales y lós emancipatorios de nuestra América. $1^{\circ}$ ed. Buenos Aires: herramienta, El colectivo. 2013.

Almeida-filho, N.; Paulani, L. M. Regulação social e acumulação por espolição: reflexão sobre a essecialização sobre as teses de financeirização e da natureza do Estado na caracterização do capitalismo contemporâneo. Economia e Sociedade, 20(2), 243-272, 2011.

Alonso, A.; Costa, V. Por uma sociologia dos conflitos ambientais no Brasil. In: Almonda, H. (Org.). Ecologia Politica: naturaleza, sociedad y utopia. Buenos Aires. Clacso. 2002. p115-137.

Barrocas, P. R.; Wasserman, J. C. O mercúrio na Baía de Guanabara: uma revisão histórica. Geochim. Brasil, 9(2), 115-127, 1995.

Bartra, A. Com lós pies sobre latierra "No nos vamos a ir". Alegatos, 85, 715-750, 2013.

Binsztok, J. A cidade do Rio de Janeiro e a cadeia produtiva do petróleo. In: Monié, F.; Binsztok, J. (Orgs.). Geografia e Geopolítica do petróleo. Manaud X. Rio de Janeiro, 2012.

Binsztok, J.; Wassermanm J. C. Considerações sobre o Complexo Petroquímico do Estado do Rio de Janeiro (COMPERJ) e sua região. In: Monié, F.; Binsztok, J. (Orgs.). Geografia e Geopolítica do petróleo. Manaud X. Rio de Janeiro, 2012.

Bourscheid. Estudo de Impacto Ambiental do sistema de dutos e terminais do COMPERJ. 2009. Disponível em $<$ http://www.observatoriodopresal.com.br/wp-content/ uploads/2011/08/volume1_cap3-\%C3\%A1rea-de-influ\%C3\%AAncia.pdf Acesso em 15 de setembro de 2014.

Brasil/mpf-icp. Inquérito Civil Públicon ${ }^{\circ} 13002000044 / 2009$ 53 - Licenciamento Ambiental - Projetos GNL e GLP da Petrobrás. Ministério Público Federal. 2009.
Bourdieu, P. Razões Práticas. Campinas, SP. Papirus editora. 2011.

Chaves, C. R. Mapeamento Participativo da Pesca Artesanal da Baía de Guanabara. Dissertação (Mestrado em Geografia) - Universidade Federal do Rio de Janeiro, Centro de Ciências Matemáticas e da Natureza, Instituto de Geociências. 2011.

Bresser-Pereira, L. C. O Novo desenvolvimentismo e a ortodoxia convencional. São Paulo em Perspectiva, 20(3), 5-24, 2006.

Bresser-Pereira, L. C.; Theuer, D. Um Estado novo-desenvolvimentista na América Latina? Economia e Sociedade, 21, Número Especial, 811-829, 2012.

Dias, A. P.; Souza, A. A.; Maia, A. B.; Berzins, F. A. J. Complexo Petroquímico do Rio de Janeiro (COMPERJ): Impactos socioambientais, violação de direitos e conflitos na Baía de Guanabara. Revista Ética e Filosofia Política, 16(1), 2013.

Diegues, A. C. Repensando e recriando as formas de apropriação comum dos espaços e dos recursos naturais. In: Diegues, A. C.; Castro, A. de (Orgs.). Espaços e recursos naturais de uso comum. São Paulo: NUPAUB-USP. 2001. 296 p.

Domingues, F. COMPERJ, uma complexa equação. In: Macaé Offshore: A revista brasileira de petróleo e gás; Ano XI, número 67/2012.

Gonçalves, R. Novo desenvolvimentismo e liberalismo enraizado. Serviço Social \& Sociedade, 112, 637-671, 2012.

Ibama. Pescadores e embarcações em atividade, produção, e valor do pescado na baía de Guanabara - abril de 2001 a março de 2002. Levantamento de dados da atividade pesqueira na baía de Guanabara como subsídio para a avaliação de impactos ambientais e a gestão da pesca. Convênio IBAMA-FEMAR. 2002. 50p.

Harvey, D. A produção capitalista do espaço. São Paulo. Annablume. 2005.

Harvey, D. O novo imperialismo. São Paulo: Loyola. 2013.

Herculano, S. Pesca e petróleo no litoral fluminense. Revista Nordestina de Ecoturismo, 4(1), 2012. 
Leher, R. Iniciativa para a Integração da Infra-Estrutura Regional da América Latina, Plano de Aceleração do Crescimento e a questão ambiental: desafios epistêmicos. In: Loureiro, C. F. B. (Org.). A questão ambiental no pensamento crítico: natureza, trabalho e educação. Rio de Janeiro. Quatert, 2007.

Lopes, J. S. L. Sobre processos de "ambientalização" dos conflitos e sobre dilemas da participação. Horizontes Antropológicos, 12(25), 31-64, 2006.

Mattei, L. Gênese e Agenda do "Novo Desenvolvimentismo Brasileiro". Anais IV Encontro Internacional da Associação Keynesiana Brasileira (AKB). Ag./2011, Rio de Janeiro.

Mercadante, A. As Bases do Novo Desenvolvimentismo no Brasil: análise do governo Lula (2003-2010). 2010. $537 f$. Tese (Doutorado em Economia) - Instituto de Economia, Universidade Estadual de Campinas, Campinas, 2010.

Mineral. Instalação do Terminal Aquaviário da Ilha Comprida, Adaptações do Terminal Aquaviário da Ilha Redonda e Dutos de GLP na Baía de Guanabara. Relatório de Impacto Ambiental (RIMA). 83p. 2007.

Oreiro, J. L; Feijo, C. Desindustrialização: conceituação, causas, efeitos e o caso brasileiro. Revista de Economia Política,30(2), 219-232, 2010.

Pinho, C. E. S. O nacional-desenvolvimentismo e o novo-desenvolvimentismo no Brasil: expansão interna, externa e o discurso social-democrata. Achegas, 45, 2012. Disponível em: http://www.achegas.net/numero/45/carlos_eduardo_45. pdf.
Planave. Relatório de Impacto Ambiental de pier e via especial de acesso para o transporte de grandes empreendimentos do Complexo Petroquímico do Estado do Rio de Janeiro (COMPERJ). 2010. 64p.

Seoane, J. Modelo extractivo y acumulacion por despojo. In: Extractivismo, despojo y mudanças climáticas: desafios para lós movimentos sociales y lós proyectos emancipatorios de nuestra América. Buenos Aires: Herramienta, El Colectivo. 2013.

Silva, L. H. P. Ambiente e justiça: sobre a utilidade do conceito de racismo ambiental no contexto brasileiro. E-cadernos ces, 17, 2012.

Siscú, J.; Paula, L. F; Michel, R. Por que Novo desenvolvimentismo? Revista de Economia Política, 27(4), 507-524, 2007.

Veríssimo, M. P.; Xavier, C. L. Tipos de commodities, taxa de câmbio e crescimento econômico: evidências da maldição dos recursos naturais para o Brasil. Revista de Economia Contemporânea, 18(2), 267-295, 2014.

Zhouri, A.; Laschefski, K.; Pereira, B. D. Desenvolvimento, sustentabilidade e conflitos socioambientais. In: Zhouri, A. (Org.). A insustentável leveza da política ambiental - desenvolvimento e conflitos socioambientais. Belo Horizonte. Autêntica. 2005.

Zibéchi, R. Los movimientossocialeslatinoamericanos:tendencias y desafíos. In: OSAL: Observatorio Social de América Latina. Buenos Aires: CLACSO. 2003. Disponível em :http://bibliotecavirtual.clacso.org.ar/ar/libros/osal/ osal9/zibechi.pdf. Acesso em: 29/04/2015. 